\title{
The effect of presenteeism-related health conditions on employee work engagement levels: A comparison between groups
}

\author{
Author: \\ Leon T. de Beer ${ }^{1}$ \\ Affiliations: \\ ${ }^{1}$ WorkWell: Research Unit for \\ Economic and Management \\ Sciences, North-West \\ University, Potchefstroom \\ Campus, South Africa \\ Correspondence to: \\ Leon de Beer \\ Email: \\ leondb@gmail.com \\ Postal address: \\ Private Bag X6001, \\ Potchefstroom 2520, \\ South Africa \\ Dates: \\ Received: 29 Mar. 2014 \\ Accepted: 18 July 2014 \\ Published: 29 Oct. 2014 \\ How to cite this article: \\ De Beer, L.T. (2014). The \\ effect of presenteeism- \\ related health conditions on \\ employee work engagement \\ levels: A comparison \\ between groups. SA \\ Journal of Human Resource \\ Management/SA Tydskrif vir \\ Menslikehulpbronbestuur, \\ 12(1), Art. \#640, 8 pages. \\ http://dx.doi.org/10.4102/ \\ sajhrm.v12i1.640

\section{Copyright:} \\ (C) 2014. The Authors. \\ Licensee: AOSIS \\ OpenJournals. This work \\ is licensed under the \\ Creative Commons \\ Attribution License.
}

Read online:
Orientation: Awareness of presenteeism-related health conditions is important as the prevalence of these conditions unknowingly influences performance and productivity in organisations.

Research purpose: The primary objective of this study was to determine the differences in work engagement levels based on groups of presenteeism-related conditions in employees.

Motivation for the study: Awareness of the impact of presenteeism-related conditions on work engagement levels can aid in the crafting of interventions to assist employees who suffer from these conditions, which in turn can boost work engagement levels.

Research design, approach and method: Cross-sectional data was collected from an availability sample of employees in the manufacturing sector $(N=3387)$.

Main findings: The results of the multi-group structural equation modelling revealed significant mean differences in work engagement levels between the groups. Practical significance tests revealed significant differences between all the groups. The largest difference was between the group who suffered from no presenteeism-related conditions and the group who suffered from all three conditions included in this study concurrently.

Practical/managerial implications: Organisational stakeholders are encouraged to take note of the effects that presenteeism-related health conditions have on work engagement and to consider relevant strategies and interventions to address and alleviate symptoms in order to tend to employee health and obviate the effect on productivity.

Contribution: This study found that there were clear practical differences between employees who suffer from the presenteeism-related conditions and those who suffer from none of the conditions. Furthermore, there was also a clear difference when comparing the 'no condition' group to a general random sample in which employees might experience some symptoms but not comorbidity.

\section{Introduction}

The global economy is still recovering from the recession of 2008. Locally, this recovery has been impeded by inter alia labour unrest through unionised strikes, both legal and illegal. Due to the slower recovery in South Africa, job forecasts have not been as optimistic as they should be and work opportunities are still scarce. Given the financial pressure that the everyday person faces, it is not a stretch of the imagination to consider that people could be present at work, but due to injury or various conditions (be they chronic or otherwise) they are not as productive as they could be. Several reasons could be postulated for this behaviour, for example the employee is paid by the hour and does not earn otherwise (Böckerman \& Laukkanen, 2010), the employee wants to be a good soldier and be available at work (Peterson, 2004), the condition is chronic and will remain a bane whether at home or at work, the employee wants to avoid any possibility of being identified for retrenchment (Dekker \& Schaufeli, 1995; Turnbull \& Wass, 2000), general work pressure (overload or deadlines), and so forth. This act of being present at work but being less productive has been coined 'presenteeism' (Dew, Keefe \& Small, 2005; Johns, 2010). Presenteeism differs from absenteeism. When absent, the supervisor or employer knows that the employee is not at work and not working, but in the case of presenteeism, the employee is at work but productivity is affected; this is obviously harder to gauge by the organisation.

Work engagement is an important organisational concept and is connected to productivity and commitment (Bakker \& Demerouti, 2008; Bakker, Demerouti \& Sanz-Vergel, 2014; Schaufeli \& Bakker, 2004). It is important from both an organisational and academic perspective that factors that affect work engagement negatively be identified and mitigated. Bakker and Leiter 
(2010) indicate that engaged employees report good health and perform well. A healthy work force is a productive work force and organisations have become more attuned to the idea that employee well-being is important for organisational performance, as health and productivity are implicitly entwined (Loeppke et al., 2009). It is therefore expected that employees with high work engagement levels would report lower presenteeism-related health conditions as they experience less discomfort and distraction due to the absence of conditions. Consequently, there may be important intervention strategies that can be applied by the organisation in order to help offset the influence that presenteeism-related health conditions have on work engagement levels; this will have a triple effect: (1) employee assistance (the moral case), (2) improving desired organisational outcomes (the business case) and (3) occupational health and safety regulations (the legal case). Even though presenteeism is not a new concept, research regarding it is relatively sparse (Johns, 2010) and even more so within the South African context. Studies have found that the financial effect of presenteeism can be estimated to be above and beyond that of normal absenteeism productivity loss for employers (Stewart, Ricci, Chee \& Morganstein, 2003), yet many organisations remain oblivious to its unseen impact.

\section{Overview of the literature Operationalising presenteeism terminology}

Even though the vast majority of research presents presenteeism as being related to reduced productivity due to health impairment, for example allergies and arthritis (Hemp, 2004; Schultz \& Edington, 2007), depression (Pilette, 2005) or obesity (Gates, Succop, Brehm, Gillespie \& Sommers, 2008), it is important to mention that other researchers have postulated that there should be no difference in terminology for those impaired by health conditions and others who are inter alia bored, distracted, under-challenged or overchallenged at work, but who do not suffer from any of these health-related conditions as these employees are also present at work but not being productive (cf. D'Abate \& Eddy, 2007; Schultz, Chen \& Edington, 2009). With regard to the latter, distinctions have been made in that healthrelated presenteeism has been referred to as 'impaired presenteeism' (for health-related presenteeism) and the other type of presenteeism that is not due to health-related impairment, but is more related to motivational aspects such as boredom, distraction or challenge, is termed 'motivational presenteeism' or 'disengagement presenteeism' (Rothmann \& Rothmann, 2007). However, all of these conceptualisations remain under the banner of presenteeism, globally. These are apt operational distinctions for researchers and practitioners in this area of research to distinguish between these two presenteeism-related concepts.

\section{Operationalising work engagement}

Work engagement is classically defined as a 'positive, work-related state of mind in employees characterised by vigour, dedication, and absorption' (Schaufeli, Salanova,
González-Romá \& Bakker, 2002, p. 74). However, later research (Schaufeli \& Bakker, 2004) has shown that the core components of work engagement need only to be considered as vigour (an energy component) and dedication (an attitude component); absorption follows as a result of being engaged at work (cf. Langelaan, 2007). Vigour is characterised by high levels of energy and mental resilience whilst working and dedication by enthusiasm, inspiration, pride and challenge in one's job (Bakker \& Demerouti, 2008; Schaufeli \& Bakker, 2004, 2010). Recent local research (De Beer, Rothmann \& Pienaar, 2012; De Bruin \& Henn, 2013; De Bruin, Hill, Henn \& Muller, 2013) has argued successfully for and operationalised work engagement as a one-factor model, consisting of, at least, vigour and dedication items. Therefore, this study also operationalised work engagement as a one-factor model, that is, a one-factor latent variable.

\section{Measuring presenteeism and productivity}

There have been important debates surrounding the measurement of presenteeism and also of productivity for research purposes (e.g. Goetzel et al., 2004; Ozminkowski, Goetzel, Chang \& Long, 2004), mainly due to the subjective nature of such ratings when employees rate themselves. Some researchers have used objective measures of productivity (e.g. number of calls made or received) (Burton, Conti, Chen, Schultz \& Edington, 2001) to attempt to overcome subjective perceptions by employees when they are rating themselves in a self-report survey. The current study was designed to adopt a novel approach in order to attempt to leapfrog the productivity and presenteeism measurement debate: work engagement was measured as this has been shown to be one of the most important indicators of employee motivation and sustained productivity (Richard, 2009). Additionally, various other desired organisational outcomes are attributed to engagement (e.g. increased commitment and reduced turnover intention) (Bakker et al., 2014; De Beer et al., 2012). Therefore, the impact of presenteeism on work engagement levels is equally important, if not perhaps more important due to the potential consequences the discomfort and pain of these conditions may have on work engagement level and consequent productivity. Three prevalent impaired presenteeism-related conditions were selected as indicators of presenteeism at work. Thus, presenteeism was also not measured directly with a self-report measure, but by three physical self-reported indicators that have been shown to be connected to it: back pain, hay fever and musculoskeletal issues (muscle aches and joint pains).

\section{Back pain, productivity and costs}

Over a period of one year, the prevalence of back pain in Germany had been estimated at 70\%; this has major economic implications (Wenig, Schmidt, Kohlmann \& Schweikert, 2009). A similar situation was found in the United States and internationally (Dagenais, Caro \& Haldeman, 2008). Back pain has also been systematically reviewed in Africa (including South Africa) and its occurrence has been found to be on the rise as the average lifetime prevalence amongst adults in 
Africa was found to be $62 \%$, which is more than one in every two adults (cf. Louw, Morris \& Grimmer-Somers, 2007). Katz (2006) found that the costs associated with back pain, specifically lower back pain, can be estimated at between $\$ 100$ and \$200 million per annum; two-thirds of this cost is due to impacted wages and diminished productivity (cf. Freburger et al., 2009). Therefore, it is obvious that back pain is a prevalent presenteeism-related condition that affects productivity, costs and profits.

\section{Allergic rhinitis (hay fever), productivity and costs}

Allergic rhinitis has been found to be associated with large direct (e.g. medical) and indirect (e.g. absenteeism) costs and therefore also with lost productivity at work (Malone, Lawson, Smith, Arrighi \& Battista, 1997). By means of objective indicators (e.g. time spent on calls in call centres), it has been found that allergy sufferers' productivity dropped by $7 \%$ when compared to co-workers who were not suffering during peak pollen season (Hemp, 2004). Hay fever is therefore considered to be an important cause of presenteeism at work and its range of symptoms can be identified inter alia by itching noses, sneezing and congestion (cf. Hemp, 2004). In terms of work time lost, employees have reported that 2.3 hours per day are spent being unproductive due to symptoms (Lamb et al., 2006). Lamb et al. (2006) also found in the United States that, in terms of cost, the mean total productivity loss for employees due to absenteeism and presenteeism was pegged at $\$ 593$ (R5930 at an exchange rate of R10.00 per \$1) per employee per year due to hay fever. Hay fever therefore has a definite effect on productivity and organisational profits.

\section{Muscle aches and pains (musculoskeletal issues), productivity and costs}

Research by the European Agency for Safety and Health at Work (EU-OSHA) found that the most prevalent work-related health problem was musculoskeletal disorders (cf. Collins \& O'Sullivan, 2010). Musculoskeletal disorders include 'a wide range of inflammatory and degenerative conditions affecting the muscles, tendons, ligaments, joints, peripheral nerves, and supporting blood vessels' (Punnett \& Wegman, 2004, p. 13). Typical everyday symptoms of musculoskeletal disorders are, inter alia, neck and shoulder pain, hand, wrist and elbow pain, ankle and foot pain and hip pain (Osborne et al., 2010). Moreover, in a Swedish sample of information technology workers, the mean score for lost time (totalled monthly) for individuals who suffered from musculoskeletal issues was found to be 17 hours (Hagberg, Wigaeus-Tornqvist \& Toomingas, 2002). This is almost equivalent to three full normal working days per month, which can be considered a significant effect on organisational productivity.

Concerning the economic impact of musculoskeletal disorders, it was found in Canada in 1994 that the total cost can be estimated at $3.4 \%$ of the gross domestic product (GDP) (CAD\$25.6 billion) (cf. Coyte, Asche, Croxford \& Chan, 1998). Furthermore, in the United States, the total cost was set at around $0.9 \%$ of the GDP at $\$ 240 \mathrm{bn}$, which included indirect costs (e.g. decreased labour force participation rate) of $\$ 98$ bn (Yelin, 2003). In a recent South African study (Naidoo, Kromhout, London, Naidoo \& Burdorf, 2009), it has been found in a sample of female workers that the incidence of musculoskeletal pain was similar to the incidence of the problem in developing countries, but that it was much higher compared to the situation in developed countries. Thus, even though no cost data was found for South Africa, it can be expected that musculoskeletal issues would also have significant economic effects in this context.

\section{The present study}

The present study focused on impaired presenteeism (health related) and how it affected work engagement levels, that is, the way work engagement levels might differ between a group of employees with the comorbidity of the conditions (i.e. they report that they do suffer from back pain, hay fever and musculoskeletal problems), a group suffering none of the conditions and a general (random) employee group (see method section below for more detail).

Given the present literature on impaired presenteeism, the expectation was that as impaired presenteeism symptoms and conditions increase that work engagement levels will decrease. The main research question for this study was therefore whether there was a significant difference in work engagement level between employees who experience none of the impaired presenteeism-related conditions, some of the impaired presenteeism-related conditions and all of the impaired presenteeism-related symptoms under investigation concurrently.

The rest of the article is structured as follows: a description of the research design (approach, method, procedures and statistical analysis). Results are then presented and discussed, also in the context of literature, and finally implications and recommendations for future research are proposed.

\section{Method \\ Research approach}

A cross-sectional survey design was used in this study. Cross-sectional designs provide for the collection of data at a single point in time, after which the data is examined to discover patterns of association (Bryman \& Bell, 2003). This design was thus deemed appropriate for the purposes of this study in order to reach its objectives.

\section{Research participants}

A random sample of employees from the manufacturing industry was collected. The mean age of participants was $37(\mathrm{SD}=12)$. The majority of participants were male $(2230$; $65.8 \%$ ), with female participants making up 34.2\% (1160) of the sample, a ratio of almost two to one. This sample makeup was not necessarily unexpected as the participants were from the manufacturing sector. The ethnic composition of the sample comprised black people $(1146 ; 33.8 \%)$ and white people $(1758 ; 51.9 \%)$. In terms of marital status, 762 
(22.5\%) participants were single, $66(2.0 \%)$ participants were engaged, 2379 (70.2\%) participants were married, 158 (4.7\%) participants were divorced and the remaining participants were widowed $(25 ; 0.6 \%)$. Regarding the 3 -month prevalence of the presenteeism-related health conditions in the sample, the following was evident: participants who indicated that they suffered from back pain numbered 902 (26.6\%), sufferers of hay fever numbered $812(24.0 \%)$ and sufferers of musculoskeletal conditions (muscle aches and pains) numbered $968(28.6 \%)$.

Participants were assigned to one of three possible groups: a comorbid group ( $n=366$; more than $10 \%$ of the sample) in which participants indicated that they suffered from hay fever, back pain and musculoskeletal issues during the previous 3 months, labelled the 'condition' group. The second group included all the participants who did not report suffering any of the aforementioned conditions during the previous 3 months, labelled the 'no condition' group ( $n=$ 1238). Lastly, the third group, labelled the 'random' group ( $n$ =1786), was created to compare with the two groups. This latter group constituted the remaining participants who may have suffered from a condition during the previous 3 months.

\section{Measuring instruments}

The South African Employee Health and Wellness Survey (SAEHWS) (De Beer et al., 2012; Rothmann \& Rothmann, 2007) was used to measure all the aspects of this study (biographical information, presenteeism and work engagement):

- Biographical information: Standard biographical questions were used to capture the age, gender and home language of each of the participants.

- Presenteeism-related conditions: Hay fever (allergic rhinitis), back pain and musculoskeletal problems (muscle aches and joint pains) were measured by simply asking participants whether they were suffering from the condition or not on a Yes or No scale: 'Over the last 3 months, have you experienced any of the following conditions?' Work engagement: This was measured by eight items (four vigour items and four dedication items) on a seven-point Likert-type scale (Never - 0 to Always 6). An example of a vigour item was 'I am full of energy in my work' and an example of a dedication item was 'I am dedicated to my work'. Reliability indicators from previous studies have shown acceptable values for this scale (e.g. = 0.89; De Beer, Pienaar \& Rothmann, 2013; De Beer et al., 2012).

\section{Statistical analysis}

Latent variable modelling methods were implemented with Mplus 7.11 (Muthén \& Muthén, 2013). A measurement model for work engagement was specified within a multigroup analysis framework with the maximum likelihood estimator. The individual items were the observed variables used to estimate a latent variable for work engagement; no item parcelling or sum scores were used. As per the guidelines discussed in Van de Schoot, Lugtig, and Hox (2012), model fit was considered with the following fit indices: comparative fit index (CFI; acceptable values between 0.90 and 0.99), Tucker-Lewis index (TLI; acceptable values between 0.90 and 0.99 ) and root mean square error of approximation (RMSEA; acceptable values between 0.01 and 0.08). Furthermore, the measurement model output also contained variances and mean scores for all groups on the estimated work engagement latent variable. As means are being compared between groups, a test for measurement invariance was necessitated as a good practice guideline; standard deviations could be calculated (square root of each variance), which enabled the calculation of effect sizes for the mean difference comparison on work engagement levels in the various groups via Cohen's $d$ with confidence intervals at the $95 \%$ level. Cohen's $d$ was interpreted in the following manner: values equal to or greater than 0.20 for a small practical effect, values greater than or equal to 0.50 for a medium practical effect and values greater than or equal to 0.80 for a large practical effect (Cohen, 1988). However, these values can be difficult to interpret for readers who are not familiar with quantitative approaches. Therefore, Cohen's $u_{3}$ values were also calculated, which provided a description of the percentage of participants that was above the mean of the participants in the control group. Finally, probability of superiority was calculated; this indicated the probability that a random person chosen from a group would have a higher mean level compared to the control group.

\section{Results}

The results section is structured as follows: firstly the reliability and measurement invariance will be discussed. Secondly, the fit of the measurement model will be reported, followed by the variances, means and standard deviations (Table 1). This is followed by the calculated effect sizes (Cohen's $d$ ) and the discussion of the mean differences, including confidence intervals of $95 \%$ (Table 2).

The results showed that the work engagement construct had acceptable reliability $(\alpha=0.91 ; \omega=0.94)$ (Raykov, 2012; Sijtsma, 2009). The test for measurement invariance revealed configural and metric invariance (Steenkamp \& Baumgartner, 1998), which indicated that the pattern of loadings, both salient and non-salient, and scale metrics were similar across groups. Furthermore, the fit indices revealed the following regarding the measurement model: CFI of 0.92 , TLI of 0.92 and RMSEA of 0.07 . The aforementioned values of all the fit indices were acceptable compared to the guidelines set before analysis and further investigation of the research questions was therefore deemed appropriate (see the statistical analysis section above).

TABLE 1: Variances, means and standard deviations of work engagement in the respective groups.

\begin{tabular}{llll}
\hline Group comparison & Variance & Mean & Standard deviation \\
\hline No condition & 0.828 & 0.000 & 0.910 \\
All conditions & 1.217 & -0.774 & 1.103 \\
Random & 1.006 & -0.331 & 1.003 \\
\hline
\end{tabular}


TABLE 2: Mean difference effect sizes with confidence intervals at the $95 \%$ level.

\begin{tabular}{llcc}
\hline Group comparison & $\begin{array}{l}\text { Cohen's d: } \\
\text { Effect size }\end{array}$ & \multicolumn{2}{c}{ Confidence interval of 95\% } \\
\cline { 2 - 4 } & & Lower & Upper \\
\hline Condition versus no condition & $0.81 \dagger$ & 0.76 & 0.86 \\
All conditions versus random & $0.43 \ddagger$ & 0.39 & 0.48 \\
No condition versus random & $0.34 \dagger$ & 0.31 & 0.38 \\
\hline
\end{tabular}

0.31 0.38

$\dagger$, large practical effect.

$t$, small practical effect.

As can be seen from the mean values (see Table 1), the 'no condition' group was used as the reference mean value by the software package in the multi-group analysis $(0.000)$. To the naked eye, both the 'condition' group (-0.774), and the 'random' group (-0.331) had lower work engagement scores compared to the 'no condition' group. But, to provide meaningful communication of practical differences in these mean values, the values were calculated for Cohen's $d$ as presented in Table 2 .

As can be seen, all of the mean differences were practically significant. The largest mean difference was indeed for the 'condition' versus the 'no condition' group $(d=0.81 ; 95 \% \mathrm{CI}$ $[0.76,0.86])$. This indicates that there was a large practical difference between the two groups, based on the $d$-value. This indicates that $79.1 \%$ of the 'no condition' group had a value that was above the work engagement mean of the 'condition' group; if one were to pick a person at random from the 'no condition' group, the chances of superiority would be $71.7 \%$ that the person would have a higher work engagement score compared to the participants in the 'condition' group.

Both of the remaining comparisons' Cohen's $d$-values showed small practical significant differences. Firstly, the 'condition' group versus the 'random' group $(d=0.43 ; 95 \% \mathrm{CI}[0.39,0.48])$. This $d$-value indicates that $66.6 \%$ of the 'random' group had a higher mean value on work engagement compared to the 'condition' group and that there was a $62.0 \%$ probability that if a participant was chosen by chance from the random group that their work engagement level would be higher compared to the 'condition' group. Secondly, the 'no condition' group versus the 'random' group ( $d=0.34 ; 95 \%$ CI $[0.31,0.38])$ also showed a small $d$-value difference. This $d$-value indicates that $63.3 \%$ of the 'no condition' group's mean scores on work engagement were above that of the other group and that there was a $59.5 \%$ probability that if a person was chosen by chance from the 'no condition' group they would have a higher work engagement mean score compared to the 'random' group.

\section{Discussion}

\section{Outline of the results}

The objective of the current research was to investigate the practical differences in work engagement level between employees with presenteeism-related health conditions, those with none of the conditions and a random group of employees who may experience one of the conditions.

The research question was answered: there was a large practical significant difference in the work engagement level of the employee group with none of the presenteeism-related health conditions and those who reported comorbidity of the conditions (all of the conditions) over the previous 3 months; in other words, the 'no condition' group had the highest work engagement level (large practical effect). This is in line with past research, which indicates that presenteeism can affect productivity (e.g. Hemp, 2004; Schultz \& Edington, 2007). The 'no condition' group had higher work engagement levels to a large practical degree. Moreover, the difference between the random group (one of the conditions) and the comorbid group (all of the conditions) was small but this implication should not be discounted based on this description as there was still a practical difference in work engagement level between employees with none of the conditions and the random sample, indicating that as impairment increases work engagement level decreases, which has the potential to affect productivity.

As the literature review revealed, the conditions as described all affect productivity; now, more credence is given to past findings as work engagement is also clearly affected at a practical level in this study. This should be of concern to organisations and relevant stakeholders as productivity is considered an outcome of good work engagement (Bakker \& Demerouti, 2008; Bakker et al., 2014; Schaufeli \& Bakker, 2004). Various arguments can be presented for the reasons why this effect on work engagement exists. As hay fever is the most common condition affecting employees (Fireman, 1997), it is not difficult to imagine that energy and attitude are affected due to experiencing hay fever symptoms whilst working. A potential intervention to address hay fever could be to investigate air quality within work areas and, if it is found to be subpar, to install air purifiers and humidifiers in order to combat potential hay fever antagonists by improving the air quality. For example, it has been found that photo-catalytic air purifiers can be used to supplement indoor ventilation when the majority of pollutants are due to building-related sources (Kolarik \& Wargocki, 2010). Furthermore, in their study, Wargocki, Wyon, Baik, Clausen and Fanger (1999) found that reducing the indoor air pollution load improved the health productivity and comfort of occupants. Therefore, such an intervention could have overall benefits for all employees whilst also attempting to address potential hay fever antagonists, especially in manufacturing-type environments.

Lower back pain can also be classified under musculoskeletal disorders and usually is, but in the current study, lower back pain was included as a separate condition due to the prevalence of the condition, according to literature (cf. Louw et al., 2007). The condition was however included in the 'condition' group for analysis with musculoskeletal issues so bias was not a concern in this regard. In South Africa, it has been found that unnatural posture is significantly associated with musculoskeletal pain at any anatomical site (Schierhout, Myers \& Bridger, 1993). A systematic review of longitudinal research has further found higher biomechanical risks 
for jobs that have excessive repetition, awkward postures and frequent heavy lifting. These are predictive of workrelated musculoskeletal disorders (Da Costa \& Vieira, 2010). Musculoskeletal issues' impact on work engagement can be due to the musculoskeletal pain in employees suffering from the condition, which puts them in a non-optimal state of functioning compared to employees who may not suffer the condition, and thus productivity is affected (cf. McDonald, DaCosta DiBonaventura \& Ullman, 2011). Therefore, it is important for organisations to consider interventions that ensure ergonomic principles are implemented and applied in working areas and that employees are aware of the correct methods of lifting medium to heavy loads (cf. Gucer, Oliver, Parrish \& McDiarmid, 2009).

Another interesting aspect of the impaired presenteeism discussion that should be presented and addressed is the potential use of medication for these conditions by employees. It has been found that, for example, a large proportion of sufferers of hay fever sufferers do not seek medical treatment (Malone et al., 1997). Those who do take medication use overthe-counter medications, which usually include sedative antihistamines, which can alter cognitive or motor function. This is concerning because if these functions are affected and impaired it may elevate the risk of a potential health and safety incident in the work place; research has found that there is a greater statistically significant probability of safety-related incidents occurring around those taking such sedative-type treatments (cf. Fireman, 1997). Similar effects can also be expected for employees who use strong pain medication due to musculoskeletal pain.

\section{Practical implications}

Presenteeism-related health conditions clearly have an effect on the work engagement levels of employees. As a result, productivity, and therefore the successful obtainment of strategic objectives and profits, can also be affected. Thus, presenteeism is a human risk factor that has a negative effect on the realisation of organisational goals. The South African Board for People Practice (SABPP, 2012), in their human resource (HR) management system standards model for South Africa, positioned HR risk managament as a crucial HR business alignment element. Therefore, $\mathrm{HR}$ risk management activities in organisations should include a measurement of presenteeism-related indicators to build awareness pertaining to these risks and the impact thereof on organisational functioning and performance, for example through an applicable climate survey. Given the identified risks, the first step that could be taken is to create an awareness of the problem of impaired presenteeism at work amongst all employees. This awareness should include potential self-help solutions, for example ergonomics or taking short breaks from sitting in front of work stations or performing other types of repetitive work tasks. Spending money in order to address the risks of presenteeism within an organisation should be thoroughly considered by employers, as the investment in this area of employee work-related wellbeing should not be above that of the incurred productivity loss due to presenteeism in the first instance. A study in the United States (Lamb et al., 2006) found that the amount per employee was around \$593 per year, but no such data could be found for the South African context. These amounts may be hard to estimate accurately, but organisations should ensure that the amount invested will provide them with sufficient returns in terms of productivity, which will be above and beyond the investment.

\section{Limitations and recommendations}

The present study was not without limitations. As with all cross-sectional survey designs, the risk of common method variance existed, but research has questioned the real impact of this potential problem (cf. Spector, 2006). Even so, objective indicators of both work engagement (e.g. performance indicators) and presenteeism-related health conditions (e.g. medical diagnoses) would have strengthened the findings of the study. Furthermore, longitudinal data is required in order to ascertain potential causal and reverse causal effects in an autoregressive cross-lagged model with at least two waves of data in the South African context. Seasonal data might be interesting in the case of hay fever, for example times when elevated pollen counts are more evident (Viander \& Koivikko, 1978). Additionally, the compounding effects of medication use for the presenteeism-related conditions could not be obviated as none of this data was available (Carruthers, Shoeman, Hignite \& Azarnoff, 1978). Other work-related well-being concepts should also be investigated in this context, such as job burnout.

\section{Conclusion}

The results of this study clearly show definite practical significant differences between the groups with regard to employee work engagement levels. The work engagement levels of the group that suffered from the comorbidity of presenteeism-related health conditions in this study showed the lowest levels of work engagement compared to those who suffered from none of the conditions, who also had the highest levels of work engagement. Put in another way, those with no presenteeism-related health conditions had the highest work engagement levels. These results add to the literature concerning work engagement and (impaired) presenteeism, especially in the South African context. Managers and other professionals should consider the potential strategies and interventions that could be applied in organisations to address hay fever, back pain and musculoskeletal issues in order to offset their influence on work engagement levels, which would lead to a more productive workforce.

\section{Acknowledgements Competing interests}

The author declares that he has no financial or personal relationship(s) that may have inappropriately influenced him in writing this article. 


\section{References}

Bakker A.B., \& Demerouti, E. (2008). Towards a model of work engagement. Career Development International, 13(3), 209-223. http://dx.doi. org/10.1108/13620430810870476

Bakker, A.B., Demerouti, E., \& Sanz-Vergel, A. (2014). Burnout and work engagement: The JD-R approach. Annual Review of Organizational Psychology and Organizational Behaviour, 1, 19.1-19.23. http://dx.doi.org/10.1146/annurevorgpsych-031413-091235

Bakker, A.B., \& Leiter, M.P. (2010). Work engagement: A handbook of essential theory and research. New York, NY: Psychology Press.

Böckerman, P., \& Laukkanen, E. (2010). What makes you work while you are sick? Evidence from a survey of workers. The European Journal of Public Health, 20(1) 43-46. http://dx.doi.org/10.1093/eurpub/ckp076

Bryman, A., \& Bell, E. (2003). Business research methods. Oxford, UK: Oxford University Press.

Burton, W.N., Conti, D.J., Chen, C.Y., Schultz, A.B., \& Edington, D.W. (2001). The impact of allergies and allergy treatment on worker productivity. Journal of Occupational and Environmental Medicine, 43(1), 64-71. http://dx.doi.org/10.1097/00043764200101000-00013

Carruthers, S.G., Shoeman, D.W., Hignite, C.E., \& Azarnoff, D.L. (1978). Correlation between plasma diphenhydramine level and sedative and antihistamine effects. Clinical Pharmacology and Therapeutics, 23(4), 375-382.

Cohen, J. (1988). Statistical power analysis for the behavioral sciences. (Rev. edn.) Orlando, FL: Academic Press.

Collins, J., \& O'Sullivan, L. (2010). Psychosocial risk exposures and musculoskeletal disorders across working-age males and females. Human Factors and Ergonomics in Manufacturing \& Service Industries, 20(4), 272-286. http://dx.doi.org/10.1002/ $\mathrm{hfm} .20220$

Coyte, P.C., Asche, C.V., Croxford, R., \& Chan, B. (1998). The economic cost of musculoskeletal disorders in Canada. Arthritis \& Rheumatism, 11(5), 315-325. http://dx.doi.org/10.1002/art.1790110503

D'Abate, C.P., \& Eddy, E.R. (2007). Engaging in personal business on the job: Extending the presenteeism construct. Human Resource Development Quarterly, 18(3), 361the presenteeism construct. Human Resource
383. http://dx.doi.org/10.1002/hrdq.1209

Da Costa, B.R., \& Vieira, E.R. (2010). Risk factors for work-related musculoskeletal disorders: A systematic review of recent longitudinal studies. American Journal of Industrial Medicine, 53(3), 285-323.

Dagenais, S., Caro, J., \& Haldeman, S. (2008). A systematic review of low back pain cost of illness studies in the United States and internationally. The Spine Journal, 8(1) 8-20. http://dx.doi.org/10.1016/j.spinee.2007.10.005

De Beer, L.T., Pienaar, J., \& Rothmann, S. Jr. (2013). Investigating the reversed causality of engagement and burnout in job demands-resources theory. SA Journal of Industrial Psychology, 39(1), 1-9. http://dx.doi.org/10.4102/sajip.v39i1.1055

De Beer, L., Rothmann, S. Jr, \& Pienaar, J. (2012). A confirmatory investigation of a job demands-resources model using a categorical estimator. Psychological Reports, 111, 528-544. http://dx.doi.org/10.2466/01.03.10.PR0.111.5.528-544

De Bruin, G.P., \& Henn, C.M. (2013). Dimensionality of the 9-item Utrecht work engagement scale (UWES-9). Psychological Reports, 112(3), 788-799. http:// dx.doi.org/10.2466/01.03.PRO.112.3.788-799

De Bruin, G.P., Hill, C., Henn, C.M., \& Muller, K.P. (2013). Dimensionality of the UWES17: An item response modelling analysis. SA Journal of Industrial Psychology, 39(2), 8 pages.

Dekker, S.W., \& Schaufeli, W.B. (1995). The effects of job insecurity on psychological health and withdrawal: A longitudinal study. Australian Psychologist, 30(1), 5763. http://dx.doi.org/10.1080/00050069508259607

Dew, K., Keefe, V., \& Small, K. (2005). 'Choosing' to work when sick: Workplace presenteeism. Social Science \& Medicine, 60(10), 2273-2282. http://dx.doi. org/10.1016/j.socscimed.2004.10.022

Fireman, P. (1997, March). Treatment of allergic rhinitis: Effect on occupation productivity and work force costs. Allergy and Asthma Proceedings, 18(2), 63-67. http://dx.doi.org/10.2500/108854197778605482

Freburger, J.K., Holmes, G.M., Agans, R.P., Jackman, A.M., Darter, J.D., Wallace, A.S et al. (2009). The rising prevalence of chronic low back pain. Archives of Internal Medicine, 169(3), 251-258. http://dx.doi.org/10.1001/archinternmed 2008.543

Gates, D.M., Succop, P., Brehm, B.J., Gillespie, G.L., \& Sommers, B.D. (2008). Obesity and presenteeism: The impact of body mass index on workplace productivity. Journal of Occupational and Environmental Medicine, 50(1), 39-45. http://dx.doi. org/10.1097/JOM.0b013e31815d8db2

Goetzel, R.Z., Long, S.R., Ozminkowski, R.J., Hawkins, K., Wang, S., \& Lynch, W. (2004) Health, absence, disability, and presenteeism cost estimates of certain physical and mental health conditions affecting US employers. Journal of Occupational and Environmental Medicine, 46(4), 398-412. http://dx.doi.org/10.1097/01. jom.0000121151.40413.bd

Gucer, P.W., Oliver, M., Parrish, J.M., \& McDiarmid, M. (2009). Work productivity impairment from musculoskeletal disorder pain in long-term caregivers. Journa of Occupational and Environmental Medicine, 51(6), 672-681. http://dx.doi. org/10.1097/JOM.0b013e31819f1d6e

Hagberg, M., Wigaeus-Tornqvist, E., \& Toomingas, A. (2002). Self-report reduced productivity due to musculoskeletal symptoms: Associations with workplace and individual factors among white-collar computer users. Journal of Occupational Rehabilitation, 12, 151-162. http://dx.doi.org/10.1023/A:1016890527520

Hemp, P. (2004). Presenteeism: At work-but out of it. Harvard Business Review, 82(10), 49-58.
Johns, G. (2010). Presenteeism in the workplace: A review and research agenda Journal of Organizational Behavior, 31(4), 519-542. http://dx.doi.org/10.1002/ job.630

Katz, J.N. (2006). Lumbar disc disorders and low-back pain: Socioeconomic factors and consequences. The Journal of Bone \& Joint Surgery, 88(2), 21-24. http://dx.doi. org/10.2106/JBJS.E.01273

Kolarik, J., \& Wargocki, P. (2010). Can a photocatalytic air purifier be used to improve the perceived air quality indoors? Indoor Air, 20(3), 255-262. http://dx.doi. org/10.1111/j.1600-0668.2010.00650.x

Lamb, C.E., Ratner, P.H., Johnson, C.E., Ambegaonkar, A.J., Joshi, A.V., Day, D. et al. (2006). Economic impact of workplace productivity losses due to allergic rhinitis compared with select medical conditions in the United States from an employe perspective. Current Medical Research and Opinion, 22, 1203-1210. http:// dx.doi.org/10.1185/030079906X112552

Langelaan, S. (2007). Burnout and work engagement: Exploring individual and psychophysiological differences. Doctoral dissertation, Department of Social and Organizational Psychology, Utrecht University, The Netherlands.

Loeppke, R., Taitel, M., Haufle, V., Parry, T., Kessler, R.C., \& Jinnett, K. (2009) Health and productivity as a business strategy: A multiemployer study. Journa of Occupational and Environmental Medicine, 51(4), 411-428. http://dx.doi. org/10.1097/JOM.0b013e3181a39180

Louw, Q.A., Morris, L.D., \& Grimmer-Somers, K. (2007). The prevalence of low back pain in Africa: A systematic review. BMC Musculoskeletal Disorders, 8(1), 105 http://dx.doi.org/10.1186/1471-2474-8-105

Malone, D.C., Lawson, K.A., Smith, D.H., Arrighi, H.M., \& Battista, C. (1997). A cost of illness study of allergic rhinitis in the United States. Journal of Allergy and Clinical Immunology, 99(1), 22-27.

McDonald, M., DaCosta DiBonaventura, M., \& Ullman, S. (2011). Musculoskeletal pain in the workforce: the effects of back, arthritis, and fibromyalgia pain on quality of life and work productivity. Journal of Occupational and Environmental
53(7), 765-770. http://dx.doi.org/10.1097/JOM.0b013e318222af81

Muthén, L.K., \& Muthén, B.O. (2013). Mplus user's guide. (7th edn.). Los Angeles, CA: Muthén \& Muthén.

Naidoo, S., Kromhout, H., London, L., Naidoo, R.N., \& Burdorf, A. (2009) Musculoskeletal pain in women working in small-scale agriculture in South Africa. American Journal of Industrial Medicine, 52(3), 202-209. http://dx.doi. org/10.1002/ajim.20662

Osborne, A., Blake, C., McNamara, J., Meredith, D., Phelan, J., \& Cunningham, C. (2010). Musculoskeletal disorders among Irish farmers. Occupational Medicine, 60(8), 598-603. http://dx.doi.org/10.1093/occmed/kqq146

Ozminkowski, R.J., Goetzel, R.Z., Chang, S., \& Long, S. (2004). The application of two health and productivity instruments at a large employer. Journal of Occupational and Environmental Medicine, 46(7), 635-648. http://dx.doi.org/10.1097/01. jom.0000131797.52458.c8

Peterson, D.K. (2004). The relationship between perceptions of corporate citizenship and organizational commitment. Business \& Society, 43(3), 296-319. http:// dx.doi.org/10.1177/0007650304268065

Pilette, P.C. (2005). Presenteeism in nursing: A clear and present danger to productivity. Journal of Nursing Administration, 35(6), 300-303. http://dx.doi. org/10.1097/00005110-200506000-00006

Punnett, L., \& Wegman, D.H. (2004). Work-related musculoskeletal disorders: The epidemiologic evidence and the debate. Journal of Electromyography and Kinesiology, 14(1), 13-23. http://dx.doi.org/10.1016/j.jelekin.2003.09.015

Raykov, T. (2012). Scale construction and development using structural equation modeling. In R.H. Hoyle (Ed.), Handbook of structural equation modeling (pp. 472-492). New York, NY: Guilford Press.

Richard, M.A. (2009). Employee assistance programs: Wellness/enhancement programming. Springfield, IL: Charles C Thomas Publisher.

Rothmann, S., \& Rothmann, J.C. (2007). The South African Employee Health and Wellness Survey (SAEHWS). User manual. (4th edn.). Potchefstroom, South Africa: Afriforte.

Schaufeli, W.B., \& Bakker, A.B. (2004). Job demands, job resources, and their relationship with burnout and engagement: A multi-sample study. Journal of Organizational Behavior, 25, 293-315. http://dx.doi.org/10.1002/job.248

Schaufeli, W.B., \& Bakker, A.B. (2010). Defining and measuring work engagement Bringing clarity to the concept. In A.B. Bakker, \& M.P. Leiter (Eds.), Work engagement: $A$ handbook of essential theory and research (pp. 10-24). New York, NY: Psychology Press.

Schaufeli, W.B., Salanova, M., González-Romá, V., \& Bakker, A.B. (2002). The measurement of engagement and burnout: A two-sample confirmatory facto analytical approach. Journal of Happiness Studies, 3, 71-92. http://dx.doi. org/10.1023/A:1015630930326

Schierhout, G.H., Myers, J.E., \& Bridger, R.S. (1993). Musculoskeletal pain and workplace ergonomic stressors in manufacturing industry in South Africa. International Journal of Industrial Ergonomics, 12(1), 3-11. http://dx.doi. org/10.1016/0169-8141(93)90033-A

Schultz, A.B., Chen, C.Y., \& Edington, D.W. (2009). The cost and impact of health conditions on presenteeism to employers. Pharmacoeconomics, 27(5), 365-378. http://dx.doi.org/10.2165/00019053-200927050-00002

Schultz, A.B., \& Edington, D.W. (2007). Employee health and presenteeism: A systematic review. Journal of Occupational Rehabilitation, 17(3), 547-579. http:// dx.doi.org/10.1007/s10926-007-9096-x

Sijtsma, K. (2009). Reliability beyond theory and into practice. Psychometrika, 74(1), 169-173. http://dx.doi.org/10.1007/s11336-008-9103-y 
South African Board for People Practice (SABPP). (2012). HR standards and metrics. Retrieved July 04, 2014, from http://www.sabpp.co.za/about/our-projects/hrRetrieved July 04, 2014,
standards-and-metrics/

Spector, P.E. (2006). Method variance in organisational research: Truth or urban legend? Organizational Research Methods, 9(2), 221-232. http://dx.doi. org/10.1177/1094428105284955

Steenkamp, J.B.E., \& Baumgartner, H. (1998). Assessing measurement invariance in cross-national consumer research. Journal of Consumer Research, 25(1), 78-107. http://dx.doi.org/10.1086/209528

Stewart, W.F., Ricci, J.A., Chee, E., \& Morganstein, D. (2003). Lost productive work time costs from health conditions in the United States: results from the American Productivity Audit. Journal of Occupational and Environmental Medicine, 45(12) 1234-1246. http://dx.doi.org/10.1097/01.jom.0000099999.27348.78

Turnbull, P., \& Wass, V. (2000). Redundancy and the paradox of job insecurity. The insecure workforce. In E. Heery, \& J. Salmon (Eds.), The insecure workforce (pp. 57-77). London, UK: Routledge. http://dx.doi.org/10.4324/9780203446485.ch4
Van de Schoot, R., Lugtig, P., \& Hox, J. (2012). A checklist for testing measurement invariance. European Journal of Developmental Psychology, 9(4), 486-492. http:// dx.doi.org/10.1080/17405629.2012.686740

Viander, M., \& Koivikko, A. (1978). The seasonal symptoms of hyposensitized and untreated hay fever patients in relation to birch pollen counts: Correlations with nasal sensitivity, prick tests and RAST. Clinical \& Experimental Allergy, 8(4), 387396. http://dx.doi.org/10.1111/j.1365-2222.1978.tb00474.x

Wargocki, P., Wyon, D.P., Baik, Y.K., Clausen, G., \& Fanger, P.O. (1999). Perceived air quality, sick building syndrome (SBS) symptoms and productivity in an office with two different pollution loads. Indoor Air, 9(3), 165-179. http://dx.doi. org/10.1111/j.1600-0668.1999.t01-1-00003.x

Wenig, C.M., Schmidt, C.O., Kohlmann, T., \& Schweikert, B. (2009). Costs of back pain in Germany. European Journal of Pain, 13(3), 280-286. http://dx.doi. org/10.1016/j.ejpain.2008.04.005

Yelin, E. (2003). Cost of musculoskeletal diseases: Impact of work disability and functional decline. The Journal of Rheumatology, 68, 8-11. 